Gut, 1983, 24, 318-325

\title{
BT-PABA test with plasma PABA measurements: evaluation of sensitivity and specificity
}

\author{
J-C DELCHIER AND J-C SOULE \\ From the Unité INSERM 99 et Service d'Hépato-Gastroentérologie, Hôpital Henri Mondor, Créteil, France
}

SUMMARY Urinary recovery and plasma time curve of PABA were determined in 15 control subjects and 65 patients during a six hour period after ingestion of a meal containing $1 \mathrm{~g}$ BT-PABA $(2 \cdot 333$ mmol PABA). In controls, the plasma PABA time curve registered a peak at two hours followed by a rapid decrease to reach its lowest value at six hours. In patients with chronic pancreatitis $(n=32)$, the peak was lower and was followed by a slow decrease; furthermore, it was delayed in those with severe pancreatic insufficiency. The best discrimination between controls and patients with chronic pancreatitis was obtained by using the maximal value of plasma PABA (MPPABA) at two or three hours. In 56 subjects a hyperbolic relationship between MPPABA and duodenal lipase output stimulated by a meal was mathematically demonstrated and it was calculated that the lower limit of normal MPPABA (mean -2 SD) corresponded to a lipase output equal to $20.6 \%$ of the mean value of normal subjects (lower limit of normal lipase output $=40 \%$ ). By comparison, steatorrhoea occurred when lipase output was less than $10 \%$. Consequently, MPPABA was low not only in all patients with steatorrhoea but also in some who had pancreatic deficiency but normal daily faecal fat. With lipase output as the reference, 12 subjects who had normal MPPABA were proved to have falsely abnormal urinary results. Urinary PABA excretion after oral administration of $2.333 \mathrm{mmol}$ free PABA was also determined in 27 subjects. The PABA excretion index (PEI) was calculated: PEI = PABA urinary excretion after BT-PABA/PABA urinary excretion after free PABA. Seven patients with normal MPPABA but low urinary excretion after BT-PABA had a normal PABA excretion index. It was also observed that, in five patients with intestinal disease, free PABA absorption was not impaired. In conclusion, BTPABA test with MPPABA determination used as an index of exocrine function is (1) less sensitive than Lundh's test, but more sensitive than steatorrhoea; (2) more specific than the test with urinary recovery determination alone, and as specific as PABA excretion index, which requires a double test.

In the last few years, a new pancreatic function test has been introduced. The test uses a substrate specific for chymotrypsin - namely, N-benzoyl-Ltyrosyl-p-aminobenzoic acid (BT-PABA). When it is split off, the p-aminobenzoic acid (PABA) moiety is rapidly absorbed by the intestinal epithelium through a passive process and almost completely excreted in the urine in acetylated form. The amount of PABA in urine collected for six or eight hours is used as an index of pancreatic function. With the use of this method, the BT-PABA test has proved useful for separating normal subjects from

Received for publication 12 July 1982 unequivocal cases of severe pancreatic insufficiency ${ }^{1-9}$ but its sensitivity, compared with that of the Lundh test and steatorrhoea, needs to be thoroughly determined. Falsely positive results have also been observed, particularly in patients with bowel or liver disease, ${ }^{3}$ as well as in subjects without obvious hepatic or digestive abnormalities."

Plasma PABA measurements should permit a more direct evaluation of BT-PABA hydrolysis by chymotrypsin. The aim of the present study is (1) to evaluate the sensitivity of BT-PABA test with plasma PABA measurements, and (2) to compare its specificity with that of the test with urinary PABA recovery. 


\section{Methods}

\section{SUBJECTS}

BT-PABA test was performed on 80 subjects who gave informed consent to the procedure. Four healthy volunteers and 11 non-alcoholic patients without organic disease of the gastrointestinal tract (eight men and seven women, aged 22 to 60 years) served as controls. Each subject had a normal Lundh test and no hepatic or renal abnormalities. Sixty-five patients ( 45 men and 20 women, aged 24 to 65 years) with symptoms suggestive of pancreatic disease (abdominal pain, unexplained weight loss, cholestatic jaundice, hyperamylasaemia, fatty diarrhoea) were selected for this study. In 32, the diagnosis of chronic pancreatitis was established either after surgery or endoscopic retrograde pancreatography. In all patients a history of alcohol abuse was found. Plasma creatinine was always below $120 \mu \mathrm{mol} / \mathrm{l}$. Liver function tests, including BSP clearance, were normal in 53 patients. Cholestatic jaundice was found in two; hepatic biopsy disclosed cirrhosis in four, steatosis in three, portal fibrosis in two, and alcoholic hepatitis in one. Two patients had histologically proven coeliac disease.

In addition, absorption of free PABA was studied in five control subjects (two men and three women, aged 30 to 68 years) and in five patients with intestinal malabsorption (two men and three women, aged 24 to 63 years). The individual diagnosis of patients with intestinal disease was coeliac disease in four and short bowel in one. In patients with coeliac disease total or subtotal villous atrophy was confined to the proximal small bowel in three and extended to the ileum in the other. In the last patient with Crohn's disease, the major part of the small bowel and the right side of the colon has been resected, leaving only $30 \mathrm{~cm}$ of the jejunum with a jejunocolic anastomosis. When the test was performed, malabsorption was present in all the patients, with massive steatorrhoea in two.

\section{Methods}

BT-PABA test was performed as follows: all drugs were discontinued at least 24 hours before and throughout the study. On the day of the test after an overnight fast, a urine specimen was collected and a blood sample was taken to serve as controls. Subjects were then given a $1 \mathrm{~g}$ dose of BT-PABA (Fluka, Busch) containing $2.333 \mathrm{mmol}$ PABA mixed in a standard liquid meal $(400 \mathrm{ml}$ water, $30 \mathrm{~g}$ corn oil, $25 \mathrm{~g}$ casein). In the next six hours, all urine passed was kept and hourly blood samples $(5 \mathrm{ml})$ were collected in heparinised tubes. The total volume of each urine specimen was recorded.
Plasma was deproteinised as previously described. ${ }^{10}$ Urine and deproteinised plasma aliquots were stored at $-20^{\circ} \mathrm{C}$ until analysis. The concentration of aromatic amines in plasma and urine samples was estimated by the Bratton and Marshall method as modified by Smith. ${ }^{11}$ Plasma concentration of PABA was expressed as $\mu \mathrm{mol} / 1$ and total recovery of PABA in the six hour urine samples was expressed as a percentage of the oral dose:

$\% \mathrm{PABA}$ recovered $=$ $\frac{\text { Total aromatic amines }(\mathrm{mmol}) \times 100}{2.333 \mathrm{mmol}}$ $2.333 \mathrm{mmol}$

In five control subjects and 22 patients, the procedure was repeated on another day but free PABA was given in an equimolar dose $(2.333 \mathrm{mmol})$ (Merck). The urinary PABA recovery was determined and a PABA excretion index (PEI) was calculated according to Mitchell. ${ }^{18}$

PEI $=$

$\% 6 \mathrm{~h}$ urinary PABA recovery from BT-PABA $\% 6 \mathrm{~h}$ urinary PABA recovery from free PABA In addition, in order to test whether the results of the BT-PABA test could be altered by intestinal malabsorption, plasma PABA time curve and urinary PABA recovery were determined after oral administration of $2.333 \mathrm{mmol}$ free PABA in five control subjects and in five patients with malabsorption.

The Lundh test - a routine procedure in our department - was performed by injecting into the stomach the liquid meal used in the BT-PABA test. Lipase mean concentration was determined in three hour collections of the duodenal contents according to the method of Zakariya as modified by Verduin, ${ }^{12}$ and lipase output was expressed as a percentage of the mean value in 42 normal subjects. A lipase output below $40 \%$ was considered as abnormal. Daily faecal fat was determined on a three day stool collection while the patients were on a $100 \mathrm{~g}$ fat daily diet. Faecal fat was determined according to the method of Van de Kamer et al. ${ }^{13}$ Normal excretion was below $7 \mathrm{~g} / 24 \mathrm{~h}$.

\section{Results}

URINARY PABA RECOVERY AND PLASMA PABA IN CONTROL SUBJECTS AND IN PATIENTS WITH CHRONIC PANCREATITIS

As shown in Fig. 1, urinary PABA recovery was $66.4 \pm 7.4 \%$ (mean $\pm \mathrm{SD}$ ) in 16 control subjects $v s$ $42.3 \pm 19.9 \%$ in 32 patients with chronic pancreatitis. The decrease was significant $(\mathrm{p}<0 \cdot 001)$, although 10 patients had values above the lower limit of normal - that is, mean value of controls -2 SD. Plasma PABA time curve was obtained in 15 control 


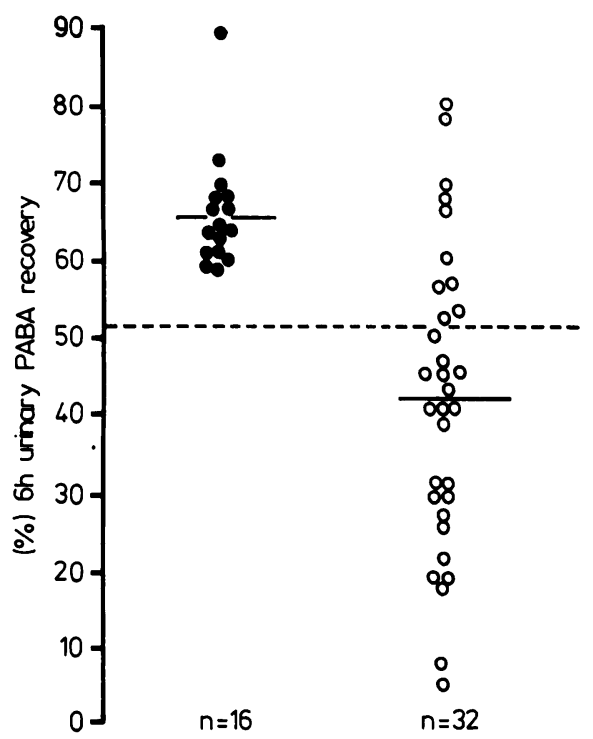

Fig. 1 Urinary $P A B A$ recovery expressed as a percentage of the oral dose in control subjects (•) and in patients with chronic pancreatitis (O). Mean value in each group (-). Lower limit of normal $=$ mean value in controls $-2 S D$ $(---)$.

subjects and in 32 patients with chronic pancreatitis (Fig. 2). In control subjects maximal plasma PABA occurred at two hours in 11 and at three hours in four; the time curve of mean plasma PABA reached a peak $(38.9 \pm 9.6 \mu \mathrm{M})$ at two hours, then sharply decreased. In patients with chronic pancreatitis, plasma PABA maximal value was observed at two hours in 15 , at three hours in five, at four hours in six, at five hours in two, at six hours in four. Therefore, the time curve had a very different shape with a lower peak at two hours followed by a slight decrease. As a result, mean plasma PABA in the latter group was significantly different from that of the control group at one, two, and three hours but not at four, five, and six hours. In patients with severe pancreatic insufficiency, a low level plateau was noted from the third hour on. When the highest of the two or three hour plasma PABA values was taken into account, the discrimination between normal subjects and patients with chronic pancreatitis was optimal. Therefore this maximal plasma PABA at two or three hours (MPPABA) was subsequently used to express the results in individual patients (Fig. 3). Mean MPPABA in control subjects was $41 \cdot 3 \pm 7 \cdot 4 \mu \mathrm{M} v s 22 \cdot 7 \pm 10 \cdot 2 \mu \mathrm{M}$ (mean $\pm \mathrm{SD}$ ) in patients with chronic pancreatitis $(p<0.001)$. Twelve of 32 patients in the latter group, however, still had a value higher than the lower limit of normal - that is, mean of control values -2 SD.

\section{CORRELATION BETWEEN MPPABA AND LIPASE} OUTPUT (Fig. 4)

Both tests were performed in 56 patients. A low MPPABA was observed in all patients with a clearly decreased lipase output $(<20 \%$ of mean value in control subjects). Values of MPPABA were in the normal range not only in all patients with normal lipase output $(<40 \%)$ but also in most patients with a mild decrease (between 20 and 40\%). When MPPABA was plotted against lipase output the distribution of points suggested a hyperbolic relationship. Such a relationship was confirmed by demonstrating a statistically very significant correlation $(p<0.001, r=0.94)$ between the values of lipase output/MPPABA and lipase output (Fig. 5). It could then be calculated that MPPABA became abnormal (lower limit of normal = mean $-2 \mathrm{SD}$ ) when the lipase output was less than $20.6 \%$ of normal. By comparison, the linear relationship between MPPABA and lipase output was significant $(\mathrm{p}<0.01)$, but the correlation coefficient was relatively low $(r=0.397)$. A good linear relationship between the two values $(p<0.01, r=0.766)$ was obtained only in patients with pancreatic insufficiency (lipase output $<40 \%$ ).
Fig. 2 Time curve of mean $P A B A$ plasma in control subjects, in patients with chronic pancreatitis and in patients with severe pancreatitis insufficiency ( $\star$ ). Value significantly different from control value $p<0.001$.

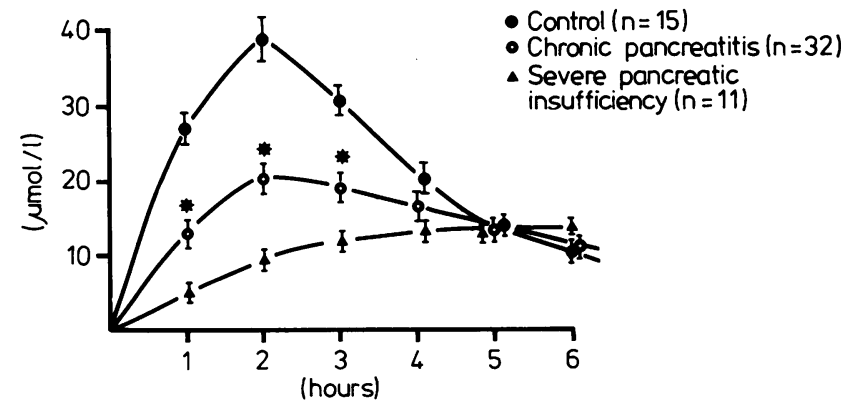




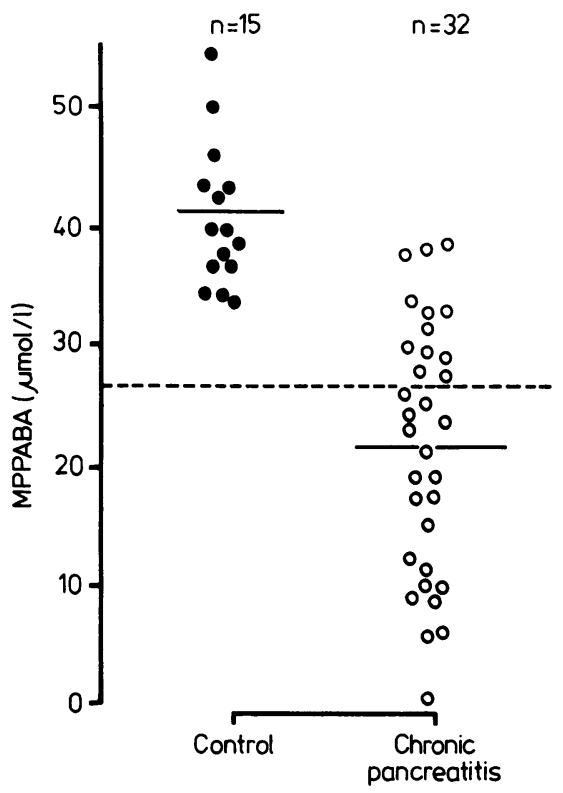

Fig. $3 M P P A B A$ in control subjects $(\bullet)$ and in patients with chronic pancreatitis (O). Mean value in each group $(-)$. Lower limit of normal = mean value in controls $-2 S D(---)$.

RELATION BETWEEN MPPABA AND STEÁTORRHOEA Lipase output, MPPABA, and daily faecal fat were measured in 52 patients. Steatorrhoea (faecal fat $>7$ g/day) was observed only in patients with lipase ouput below $10 \%$ of normal. MPPABA was abnormal not only in all the 14 patients with steatorrhoea but also in seven patients with normal faecal fat (Fig. 6).

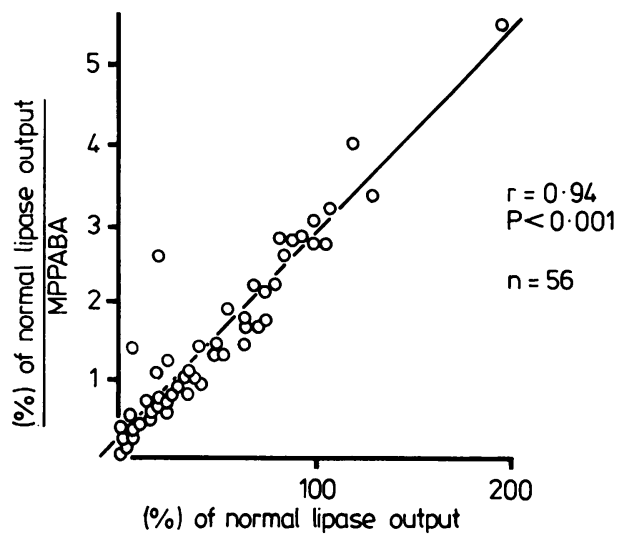

Fig. 5 Correlation of lipase output/MPPABA with lipase output in 56 subjects.

COMPARATIVE SENSITIVITY OF BT-PABA, LUNDH TEST, AND DAILY FAECAL FAT IN DIAGNOSIS OF CHRONIC PANCREATITIS

As shown in Table 1 , the most sensitive pancreatic function test for the diagnosis of chronic pancreatitis was the Lundh test. But MPPABA was more sensitive than daily faecal fat.

\section{RELATION BETWEEN MPPABA AND URINARY PABA} RECOVERY

In the 80 subjects who were investigated, MPPABA and urinary PABA recovery values were generally in agreement and significantly correlated $(r=0.772$, $\mathrm{p}<0.001$ ) (Fig. 7). An abnormal value of PABA urinary recovery with a normal MPPABA was noted, however, in 16 patients. Lundh test was performed in 12 of these subjects (Table 2).
Fig. 4 Comparison of MPPABA with duodenal lipase output in 56 subjects. Patients with (•) and without (O) chronic pancreatitis. Lower limit of normal lipase output $=40 \%$ of the mean value in 42 normal subjects.

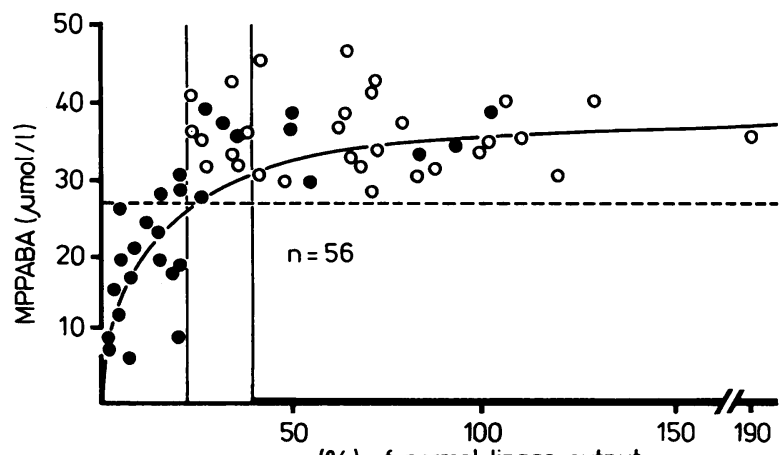

$(\%)$ of normal lipase output 
Fig. 6 Comparison of MPPABA with daily faecal fat. Upper limit of normal daily faecal fat $=7 \mathrm{~g}$. Lower limit of normal $M P P A B A=26 \cdot 5 \mu M$.

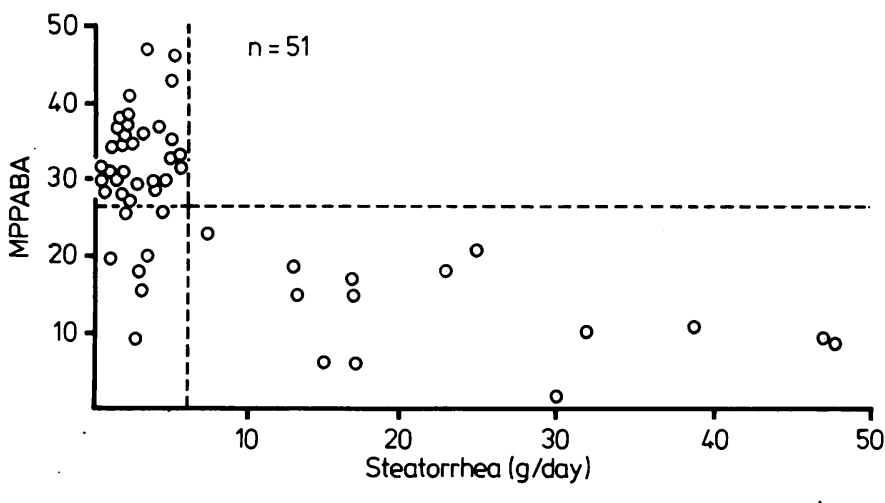

MPPABA was certainly correct and urinary results falsely positive in seven patients who had a normal lipase output. In five patients, lipase output was decreased but higher than $25 \%$ of normal; MPPABA was also probably correct, as enzyme output exceeded the threshold above which MPPABA was always found to be normal.

Falsely positive urinary results might be related to a decrease in the urinary excretion capacity. To test this hypothesis, urinary PABA recovery was determined on separate occasions in 22 patients and five control subjects after oral BT-PABA and after administration of $2.333 \mathrm{mmol}$ free PABA (Fig. 8). PABA excretion index was calculated as previously indicated. As shown in Fig. 8, MPPABA was abnormal in all the patients with an index of less than 0.8 and normal in all the subjects with an index above $\mathbf{0} \cdot 8$. In this latter group, seven subjects had a borderline or slightly low urinary PABA recovery after BT-PABA administration. As their PABA excretion index was normal, the low urinary excretion after oral BT-PABA could be explained only by a low PABA excretion capacity. Thus, it does appear that (1) MPPABA constantly agrees with PABA excretion index but not with urinary PABA recovery after oral BT-PABA, and (2) in patients with normal MPPABA, low urinary PABA recovery is due to low urinary PABA excretion capacity and has to be considered as falsely positive.

Table 1 Sensitivity of three tests in diagnosis of chronic pancreatitis

\begin{tabular}{llll}
\hline & $\begin{array}{l}\text { Chronic } \\
\text { pancreatitis } \\
\text { (no.) }\end{array}$ & $\begin{array}{l}\text { Abnormal } \\
\text { (no.) }\end{array}$ & $\begin{array}{l}\text { Abnormal } \\
(\%)\end{array}$ \\
\hline Steatorrhoea & 32 & 15 & 47 \\
MPPABA & 32 & 20 & $62 \cdot 5$ \\
Lipase & 30 & 24 & 80 \\
\hline
\end{tabular}

ABSORPTION OF FREE PABA IN PATIENTS WITH INTESTINAL DISEASE

As shown in Fig. 9, mean plasma time curve and urinary PABA recovery did not significantly differ in controls and in patients with intestinal disease. A control subject with normal serum creatinine level (100 $\mu \mathrm{mol} / \mathrm{l})$ had a low urinary PABA excretion capacity. He had, in fact, a low urinary recovery, whereas his plasma PABA values were rather high.

\section{Discussion}

For the first time, hourly plasma concentration and urinary PABA recovery were both routinely

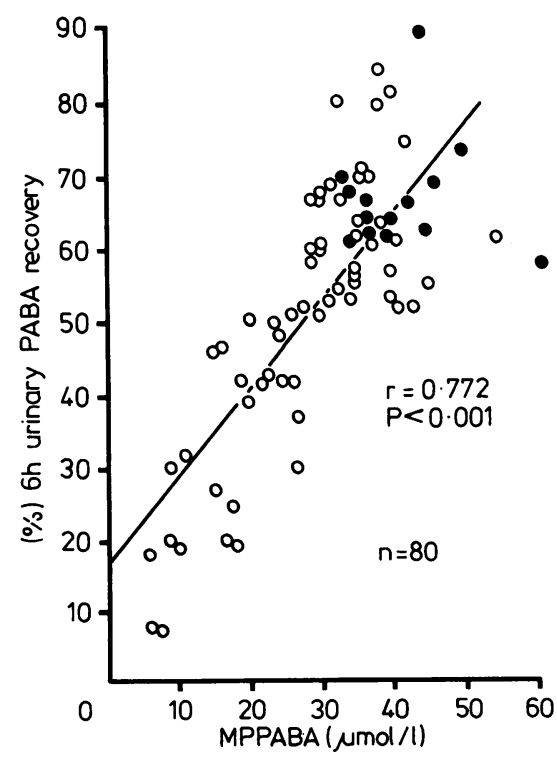

Fig. 7 Correlation of urinary $P A B A$ recovery and MPPABA in 80 subjects. Controls $(\bullet)$ and patients $(\circ)$. 
Table 2 Patients with normal MPPABA and low urinary $P A B A$ recovery

\begin{tabular}{|c|c|c|c|c|c|c|c|}
\hline Name & $\begin{array}{l}\text { Age } \\
(y r)\end{array}$ & Sex & $\begin{array}{l}6 \text { hour urinary } \\
\text { excretion of } \\
P A B A \\
(N>51.6 \%)\end{array}$ & $\begin{array}{l}\text { MPPABA } \\
(N>26.5 \mu \mathrm{mol} / \mathrm{l})\end{array}$ & $\begin{array}{l}\text { Lipase output } \\
(N>40 \%)\end{array}$ & Liver disease & $\begin{array}{l}\text { Serum } \\
\text { creatinine } \\
\text { ( } \mu \text { mollll) }\end{array}$ \\
\hline MOI & 60 & $\mathbf{F}$ & $39 \cdot 7$ & $33 \cdot 3$ & 26 & 0 & 50 \\
\hline LAR & 42 & $\mathbf{M}$ & 46 & 37.9 & 49 & Steatosis & 40 \\
\hline DRE & 40 & $\mathbf{M}$ & $50 \cdot 7$ & 37 & 64 & 0 & 70 \\
\hline BRI & 55 & $F$ & $47 \cdot 2$ & 36 & $25 \cdot 5$ & 0 & 65 \\
\hline RAL & 41 & $\mathbf{M}$ & 46 & $46 \cdot 9$ & 66 & Alcoholic hepatitis & 45 \\
\hline FRAI & 43 & $\mathbf{M}$ & $39 \cdot 4$ & $38 \cdot 6$ & 26 & 0 & 43 \\
\hline LEB & 45 & $\mathbf{M}$ & $44 \cdot 3$ & 34 & 50 & 0 & 81 \\
\hline SIL & 50 & $\mathbf{M}$ & $26 \cdot 1$ & 29 & 71 & 0 & 75 \\
\hline ISE & 52 & $\mathbf{M}$ & 47 & $31 \cdot 2$ & 40 & 0 & 60 \\
\hline ORM & 40 & $\mathbf{M}$ & 45 & $31 \cdot 4$ & 29 & 0 & 45 \\
\hline LEP & 42 & $\mathbf{M}$ & $45 \cdot 3$ & $30 \cdot 4$ & $25 \cdot 5$ & 0 & 53 \\
\hline DOL & 44 & $\mathbf{M}$ & $30 \cdot 6$ & $32 \cdot 6$ & 68 & 0 & 85 \\
\hline
\end{tabular}

measured in the six hours after oral administration of $1 \mathrm{~g}$ BT-PABA in a test meal. Where urinary PABA recovery was concerned, our results agree fairly well with those of $\mathrm{Gyr}^{2}$ who performed the test in the same conditions. Plasma time curves yielded interesting results: they were very different in subjects with and without pancreatic insufficiency and analysis clearly showed that the best discrimination was obtained by considering maximal value in the second or third hour samples. The shape of plasma time curves in controls is probably related to the rapid degradation of ingested substrate by chymotrypsin in the duodenum, followed by rapid intestinal absorption and renal elimination of PABA. In patients with chronic pancreatitis - and particularly in those with severe pancreatic insufficiency - it probably reflects the delayed hydrolysis of the substrate due to a reduced amount of enzyme. Hydrolysis would then continue during the transit of the test meal through the entire bowel and would be ultimately more or less carried out by the microflora of the large bowel. ${ }^{14}$

In our study, although it indirectly evaluates chymotrypsin activity, MPPABA was compared with duodenal lipase output. This comparison is valid, as the secretion of different pancreatic enzymes has been reported to be parallel. ${ }^{15-17}$ The type of correlation between urinary PABA recovery and the output of stimulated bicarbonate and/or enzyme is still debated. Most authors, accumulating data from subjects with and without enzyme deficiency, found the correlation to be linear. ${ }^{13-8}$ We also demonstrated such a linear relationship but we did find that an hyperbolic type of correlation to be much more significant. A linear relationship can be expected in patients with pancreatic deficiency in whom substrate largely exceeds the enzyme. We showed, as did Gyr, ${ }^{2}$ that, in these patients, linear correlation was very good. When all patients with and without pancreatic insufficiency are pooled, however, the hyperbolic relationship between enzyme output and MPPABA is completely predictable: (1) in subjects with borderline and/or normal enzyme output, the enzyme can be expected to become progressively in excess, which accounts for the tendency of the curve to reach an asymptote;
Fig. 8 Comparison of urinary $P A B A$ recovery after oral $B T-P A B A$ and $P A B A$ excretion index. $P E I=\frac{\text { Urinary } P A B A \text { recovery after } B T-P A B A}{\text { Urinary } P A B A \text { recovery after free } P A B A}$

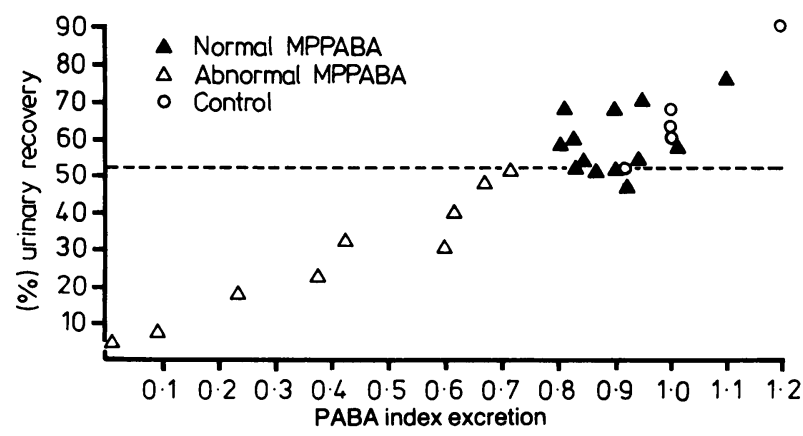


Fig. 9 Plasma PABA time curve (mean $\pm S E M$ ) and six hour urinary $P A B A$ recovery (- mean value) in five control subjects $(\bullet)$ and in five patients with intestinal malabsorption (O).

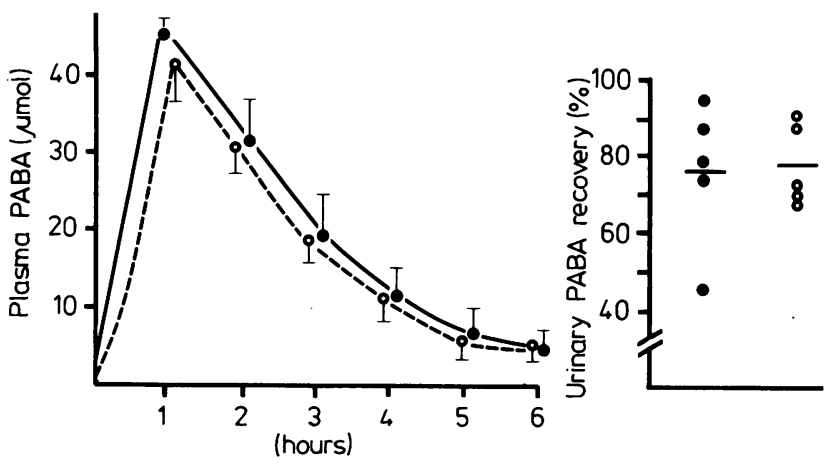

and (2) the initial part of a hyperbole does not deviate much from a straight line. It should also be noted that the diagrams of $\mathrm{Gyr}^{2}$ and Hoeck obviously suggest such a relationship. In our study, we calculated that lipase output had to be less than $20.6 \%$ of normal for MPPABA to be abnormal (sensitivity threshold of MPPABA). Individual results are quite consistent with this calculated threshold: MPPABA was always normal when lipase output was above $25 \%$ and always abnormal when lipase output was below $18 \%$. Such a welldefined threshold could not be established by Hoeck et $a l^{\vartheta}$ who observed a very large range (from very low to strictly normal value) in urinary PABA recovery in patients with a mildly decreased trypsin output. They claimed that variations of duodenal $\mathrm{pH}$ could account for variable PABA urinary excretion in patients with mild pancreatic deficiency but provided data only from in vitro experiences. We feel that the influence of $\mathrm{pH}$ was probably overestimated and that the scattering of urinary PABA recoveries may have been due to falsely positive results which could have been corrected by using MPPABA measurements.

From comparison of the respective relationships of MPPABA and steatorrhoea with lipase output, it could be presumed that the BT-PABA test with plasma measurements was a more sensitive index of pancreatic function than steatorrhoea, as daily faecal fat and MPPABA became abnormal when lipase output values were respectively below $10 \%$ and $20 \%$ of normal. Individual results emphasised the greater sensitivity of MPPABA: it was abnormal not only in all patients with steatorrhoea but also in some with pancreatic deficiency but normal daily faecal fat.

Evidence of falsely positive urinary results can be demonstrated by determination of the PABA excretion index: this index was, indeed, found to be normal in patients with abnormal PABA recovery but with normal pancreatic function as assessed by the Lundh test. ${ }^{18}$ In our study, comparison in the same patients of the values of MPPABA and PABA urinary excretion with enzyme output clearly showed that plasma PABA measurements increased the specificity of the test. Moreover, patients with low urinary recovery but a normal PABA excretion index had normal MPPABA. It thus appears that MPPABA determination gives to the BT-PABA test a specificity equal to that of PABA excretion index without requiring a double test.

Impairment in absorption or hepatic conjugation has been claimed to account for falsely positive urinary results in patients with various bowel or liver diseases. ${ }^{3}$ In our experience, liver abnormalities had little effect upon PABA excretion. We observed no real disagreement between normal MPPABA and low urinary PABA recovery in patients with liver disease. We also demonstrated that absorption of free PABA was not significantly different from normal in five patients with proven intestinal malabsorption. This contradicts the findings of Mitchell et $\mathrm{al}^{3}{ }^{18}$ who reported a low urinary PABA recovery with normal PABA excretion index in patients with intestinal disease. The large doses used by these authors ( $2 \mathrm{~g} \mathrm{BT-PABA}$ - that is, 4.666 mmol PABA) could have revealed malabsorption of PABA. It must be pointed out, however, that PABA malabsorption was not shown, as low urinary PABA recovery might have been a result of decreased renal excretion capacity. We think, therefore, that, at least with the $1 \mathrm{~g}$ dose of BT-PABA, low MPPABA in a patient with intestinal disease has to be considered as indicating pancreatic dysfunction.

\section{References}

1 Arvanitakis C, Greenberger NJ. Diagnosis of pancreatic disease by a synthetic peptide. Lancet 1976 ; 1: 663-6. 
2 Gyr K, Stalder GA, Schiffmann C, Fehr C, Vonderschmitt D, Fahrlaender H. Oral administration of a chymotrypsin-labile peptide - a new test of exocrine pancreatic function in man (PFT). Gut 1976; 17: 27-32.

3 Mitchell CJ, Humphrey CS, Bullen AW, Kelleher J. The diagnostic value of the oral pancreatic function test. Scand J Gastroenterol 1978; 14: 183-7.

4 Nousia-Arvanitakis S, Arvanitakis C, Desai N, Greenberger NJ. Diagnosis of exocrine pancreatic insufficiency in cystic fibrosis by the synthetic peptide N-benzoyl-L-tyrosyl-p-aminobenzoic acid. $J$ Pediatr 1978; 92: 734-7.

5 Imamura $\mathrm{K}$, Nakamura $\mathrm{T}$, Miyazawa $\mathrm{T}$, Abe $\mathrm{Y}$, Kobayashi $\mathbf{M}$, Takebe $\mathbf{K}$. Oral administration of chymotrypsin labile peptide for a new test of exocrine pancreatic function (PFT) in comparison with pancreozymin-secretin test. Am J Gastroenterol 1978; 69: 572-8.

6 Ribet A, Frexinos J, Escourrou J, Vaysse N, Arany Y, Varignon M. Étude indirecte de la sécrétion exocrine du pancréas par administration orale d'un peptide synthétique (PABA test). Gastroenterol Clin Biol 1979; 3: 227-34.

7 Harada H, Mishima K, Shundo T, et al. Exocrine pancreatic function test by a synthetic peptide. Am J Gastroenterol 1979; 71: 45-52.

8 Kimura $\mathrm{T}$, Wakasugi $\mathrm{H}$, Ibayashi $\mathrm{H}$. Clinical study of exocrine pancreatic function test by oral administration of N-benzoyl-L-tyrosol-p-aminobenzoic acid. Digestion 1981; 21: 133-9.

9 Hoek FJ, Sanders GTB, Teunen A, Tijtgat GNJ. In vitro and in vivo analysis of the PABA test compared with the Lundh test - influence of intraluminal $\mathrm{pH}$. Gut 1981; 22: 8-14.
10 Batt RM, Bush BM, Peters TJ. A new test for the diagnosis of exocrine pancreatic insufficiency in the dog. J Small Anim Pract 1979; 20: 185-92.

11 Smith HW, Finkelstein N, Aliminosa L, Crawford B, Graber $\mathrm{M}$. The renal clearances of substituted hippuric acid derivatives and other aromatic acids in dog and man. J Clin Invest 1945; 24: 388-404.

12 Verduin PA, Punt JMHM, Kreutzer HH. Studies on the determination of lipase activity. Clin Chim Acta 1973; 46: 11-19.

13 Van de Kamer JH, Huinink HTB, Weyers HA. Rapid method for the determination of fat in feces. $J$ Biol Chem 1949; 177: 347-55.

14 Imondi AR, Stradley RP, Wolgemuth R. Synthetic peptides in the diagnosis of exocrine pancreatic insufficiency in animals. Gut 1972; 13: 726-31.

15 Burton P, Evans DG, Harper AA, Howat HT, Oleesky. S, Scott JE, Varley H. A test of pancreatic function based on the analysis of duodenal contents after administration of secretin and pancreozymin. Gut 1960; 1: 111-24.

16 Robberecht P, Cremer M, Vandermeers A, Vandermeers-Piret MC, Cotton P, De Neef P, Christophe J. Pancreatic secretion of total protein and of three hydrolases collected in healthy subjects via duodenoscopic cannulation. Gastroenterology 1975; 69: 374-9.

17 Escourrou J, Frexinos J, Ribet A. Étude de la sécrétion pancréatique pure chez l'homme sous stimulation par sécrétine-céruléine. Gastroenterol Clin Biol 1978; 2: 29-37.

18 Mitchell CJ, Humphrey CS, Bullen AW, Kelleher J, Losowsky MS. Improved diagnostic accuracy of a modified oral pancreatic function test. Scand J Gastroenterol 1979; 14: 737-41. 